\section{The "Healthy Habits, Healthy Girls" randomized controlled trial for girls: study design, protocol, and baseline results}

\author{
Ensaio randomizado controlado para meninas \\ "Hábitos Saudáveis, Meninas Saudáveis": \\ delineamento, protocolo de estudo e \\ resultados do baseline
}

\author{
Ensayo randomizado controlado para niñas \\ "Hábitos Saludables, Niñas Saludables": \\ delineación, protocolo de estudio y \\ resultados iniciales
}

A

The purpose of this article is to describe the study design, protocol, and baseline results of the "Healthy Habits, Healthy Girls" program. The intervention is being evaluated through a randomized controlled trial in 10 public schools in the city of São Paulo, Brazil. Data on the following variables were collected and assessed at baseline and will be reevaluated at 7 and 12 months: body mass index, waist circumference, dietary intake, nutrition, physical activity, social cognitive mediators, physical activity level, sedentary behaviors, self-rated physical status, and overall self-esteem. According to the baseline results, $32.4 \%$ and $23.4 \%$ of girls were overweight in the intervention and control groups, respectively, and in both groups a higher percentage failed to meet daily recommendations for moderate and vigorous physical activity and maximum screen time (TV, computer, mobile devices). There were no significant differences between the groups for most of the variables, except age ( $p=0.000)$ and waist circumference $(p=0.014)$. The study showed a gap in the Brazilian literature on protocols for randomized controlled trials to prevent obesity among youth. The current study may thus be an important initial contribution to the field.

Adolescent; Feeding Behavior; Motor Activity; Obesity
Ana Carolina Barco Leme 1 Sonia Tucunduva Philippi 1

\section{Resumo}

O objetivo deste artigo é descrever o delineamento, protocolo de estudo e resultados do baseline do programa "Hábitos Saudáveis, Meninas Saudáveis". A intervenção será avaliada por meio de um ensaio randomizado controlado em 10 escolas públicas de São Paulo, Brasil. As variáveis foram mensuradas no baseline e serão avaliadas após 7 e 12 meses do baseline: índice de massa corporal, circunferência da cintura, dieta, mediadores sociais cognitivos da nutrição e atividade física, nível de atividade física, comportamentos sedentários, autopercepção física e autoestima global. Resultados do baseline demonstraram que 32,4\% do grupo intervenção $e$ 23,4\% do controle estavam acima do peso, e para ambos uma grande porcentagem não atingiu as recomendações diárias de atividade física moderada/vigorosa, e tempo de tela. Para a maioria das variáveis, com exceção de idade $(p=0,000) e$ circunferência da cintura $(p=0,014)$, não houve diferença significante entre os grupos. Há uma lacuna na literatura brasileira sobre ensaios randomizados controlados para prevenir obesidade em adolescentes. Este trabalho pode apresentar uma importante contribuição para a área.

Adolescente; Comportamento Alimentar; Atividade Motora; Obesidade 


\section{Introduction}

Regular physical activity (PA), limited screen time, and healthy eating habits have been shown to protect against unhealthy weight gain 1 . However, evidence shows that many adolescents fail to follow the recommended levels for PA and healthy eating or to restrict their screen time to two hours or less per day 1,2 .

Calls have been issued for strategies to systematically change the environment for PA and nutrition in order to foster healthy behaviors and thus help prevent weight-related problems 3 . Schools are an ideal setting for such interventions, because healthy behavior patterns established at school age and in school settings provide the opportunity for interventions addressed to the majority of youth, in a safe environment, and with specifically trained educators 3,4 . Nonetheless, school-based interventions to promote healthy behaviors among adolescents have enjoyed mixed success 5 , including programs in Brazil 3. The factors for successful strategies in Brazil are still under development. Previous studies have not focused on groups of people with similar characteristics (e.g., adolescent girls from disadvantaged backgrounds) or multivariate and interactive lifestyle influences (diet, PA, sedentary behaviors, and family) which can combine in complex ways to exert a cumulative effect on body weight 2 .

Such research has important public health implications, because understanding which behaviors need to be targeted simultaneously and the ways that weight problems cluster in one person can be used to assist the development of targeted initiatives to promote healthy habits. Appropriately targeted interventions that effectively lead to multiple behavior changes can be cost-effective and maximize the impact for those most in need 2 . For example, unhealthy behaviors are common during adolescence, especially among girls from disadvantaged backgrounds, thus placing this group at increased risk for unhealthy weight gain 1,2. Methodologically rigorous trials targeting economically disadvantaged groups, tailored to gender, and combining multiple behaviors are clearly needed in Brazil. The current article describes the study design and baseline findings from the "Healthy Habits, Healthy Girls" program, an innovative schoolbased intervention that combines a range of evidence-based behavior-change strategies to promote healthy eating and PA and to prevent unhealthy weight in adolescent girls from lowincome communities.

\section{Methods}

\section{Study design}

The "Healthy Habits, Healthy Girls" program is a randomized controlled trial (RCT) (Figure 1) investigating a 6-month multiple-component school-based nutrition and PA program for adolescent girls enrolled in the second and third years of 10 public high schools in the city of São Paulo, Brazil. Assessments were conducted at baseline [February (Term 1) 2014], repeated postprogram [September (Term 3)], and will be done at 12 months post baseline [February (Term 1)]. Follow-up data collection for the hypothesized mediators will take place in Term 3, 2014 (August). The study design, implementation, and reporting comply with the Consolidated Standards of Reporting Trials (CONSORT) 6. Ethical approval for this study was obtained from the Ethics Research Committee of the School of Public Health, University of São Paulo, Brazil. School principals, teachers, parents, and study participants provided written informed consent.

\section{Sample size}

A power calculation was conducted to determine the sample size required to detect changes in the primary outcome, i.e., body mass index (BMI) at the primary end-point of six months 7,8 . The sample size was based on the results of the NEAT Girls intervention program at 12 months 7 . Sample size was calculated for $80 \%$ power, $5 \%$ significance ( $\mathrm{p} \leq 0.05$ ), and the proportion of unexposed and exposed with the outcome (56.6\% healthy weight vs. $42.9 \%$ unhealthy weight). Considering $20 \%$ potential dropout at six months, the study aimed to recruit 266 participants from 10 schools (a mean of 25 per school).

\section{Participants}

The Human Development Index (HDI) was used to identify eligible high schools. The HDI is a comparable measurement of wealth, life expectancy, education, literacy, foreign birth, and other factors for several countries worldwide. There is no low HDI in the city of São Paulo. Therefore, schools located in census tracts with medium HDI were considered eligible. Public high schools located in different low-income areas of the city of São Paulo with medium HDI and at least 100 students in the target year bracket were eligible to participate in the study. From 13 eligible high schools, 12 schools were contacted, with recruitment successfully performed in 10 . 
Study design and flow.

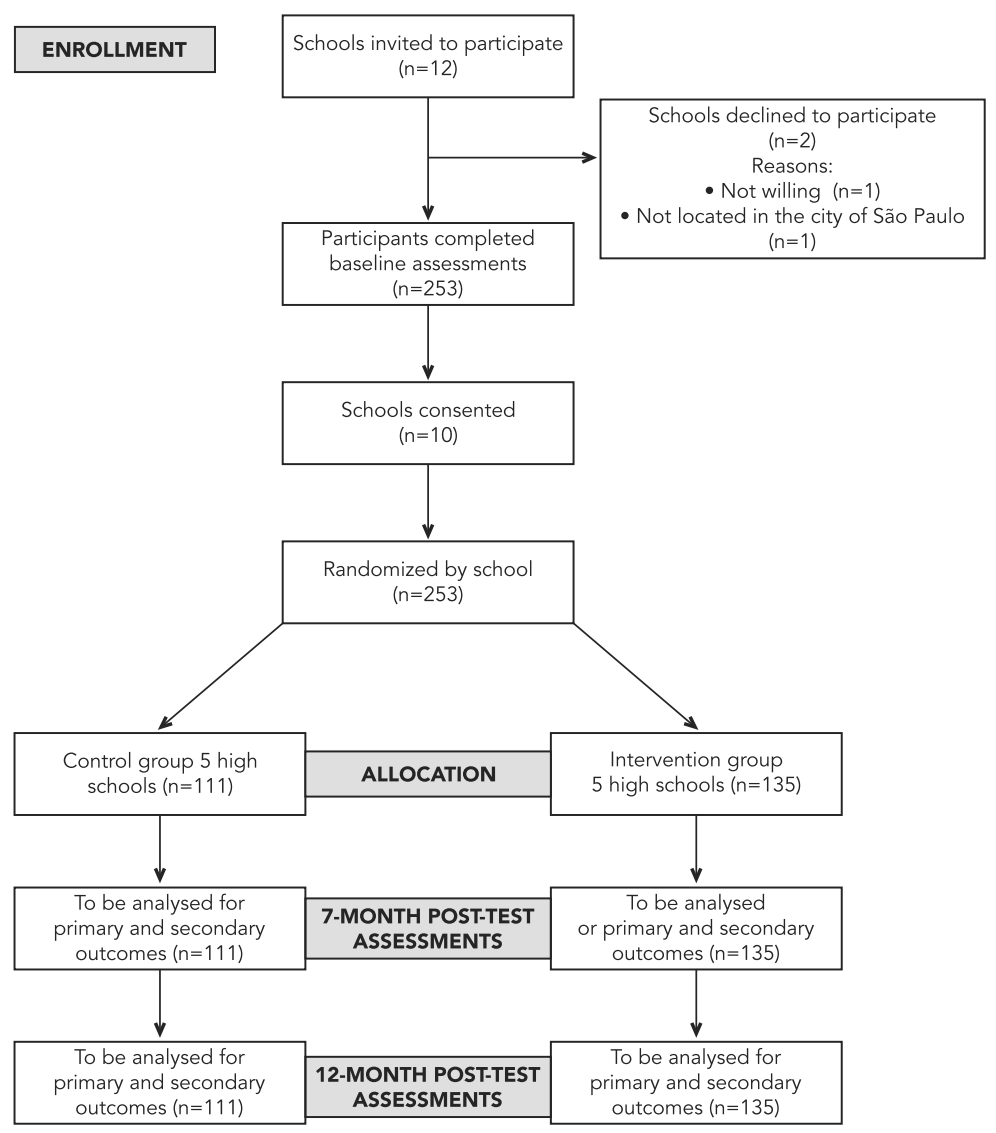

Prior to baseline assessment, all female students in the target year bracket at the 10 schools were asked to complete a four-item screening questionnaire. The questionnaires were used to identify students "at risk" of obesity based on their health behaviors. "At risk" was defined as failing to meet current recommendations for healthy eating and PA 9,10. All eligible students received information and consent forms. The target for recruitment was 25 students per school, but up to 30 students from each school could be accepted ${ }^{8}$. The 30 first students from each school to return their completed consent forms were included in the study.

\section{Blinding and randomization}

Recruitment and baseline assessments were conducted prior to randomization. The 10 schools were match-paired (5 pairs of schools) based on geographic location, size, and demographics. Schools within each pair were then randomized to either the "Healthy Habits, Healthy Girls" intervention or a waiting-list control group by an individual not involved in the research project. Schools remained in their allocated group for the duration of the study. Trained research assistants (RA) conducted baseline assessments, and wherever possible, post-test assessment was also conducted by RAs blinded to group allocation.

\section{Intervention}

"Healthy Habits, Healthy Girls" is a multicomponent school-based intervention with the following activities: enhanced physical education classes, physical activities during recess, weekly 
nutritional and PA messages, nutrition and PA handbooks, interactive seminars, nutrition workshops, parents' newsletters, text messages, and dietary and PA diaries for adolescent girls (Table 1). The intervention is based on the NEAT Girls RCT 9,11 conducted in 12 secondary schools in the Hunter Region, New South Wales, Australia. The theoretical reference was Bandura's Social Cognitive Theory (SCT) 12,13. Intervention components were developed using taxonomy of behavior change strategies 14 and designed to target potential mediators of behavior change in nutrition and PA. "Healthy Habits, Healthy Girls" aims to promote low-cost lifetime and lifestyle activities focusing on nutrition and PA. The activities were delivered over three school terms (6 months) at no cost to the schools or students. Lifetime health activities are those that may be easily carried over into adulthood and generally require only one or two people to participate (cooking healthy recipes and walking) 7 . Lifestyle activities are those performed as part of everyday life, such as walking to school and drinking water 7 .

\section{- Enhanced physical education classes}

Enhanced physical education (PE) classes were delivered by PE teachers and included the following: warm-up, stretch exercises, dance, resistance training, skipping rope, and boxing fitness. Different dance styles were performed with the students. PE teachers and girls brought their favorite music and created choreographies. Stretch exercises were conducted at the beginning and end of the classes. Classes were organized into 4 -week units, and the girls selected the sequencing of activities, e.g., boxing for 4 weeks followed by 4 weeks of dancing.

\section{- PA sessions during recess}

The girls received a PA leadership book with all the activities delivered during the PE classes in order to be able to act as multiplying agents of PA habits in school. During recess, as a complement to the enhanced PE class, the participants engaged in PA sessions and passed on what they had learned to younger girls from lower grades. The sessions lasted 20 minutes and occurred twice a week in the second and third terms. They were organized into 2-week units with the sequence selected by the participating girls under supervision by the PE teacher.

\section{- Weekly nutrition and PA messages}

For the first and second school terms, teachers from each intervention school delivered an information component with the 10 key health messages (Table 2). Information components were delivered weekly during recess for 10 to 15 minutes. Researchers from the School of Public Health, University of São Paulo, trained the teachers in advance.

\section{- Interactive seminars}

Two dietitians conducted three interactive 60-minute seminars and reinforced the 10 nutritional and PA key messages. The seminars were conducted such that information was delivered interactively on healthy eating, PA, and sedentary behaviors. The girls provided questions, suggestions, and social support creating the basis for long-term behavior change.

\section{- Nutrition and PA handbook}

The handbook features the 10 key messages with information and home challenges designed to promote healthy eating and PA among study participants and parents.

\section{- Nutrition workshops}

Two dietitians delivered three practical nutrition workshops, focused on dietary information and strategies to develop lifetime nutritional skills that facilitate maintaining healthy weight. Topics included food label reading, the energy balance and kilocalories concepts, definitions of "diet" and "light" products, total fat and sugar in foods, adequate portions, and preparation of inexpensive healthy snacks and meals.

\section{- Dietary and PA diaries}

Participants kept diaries to encourage goal-setting and self-monitoring of healthy behaviors for use on weekends and school holidays.

\section{- Parents' newsletters}

Newsletters were sent to parents/caregivers four times over the 6-month intervention (i.e., April, May, July, and August). The newsletters described the program content and study progress, including participants' nutritional status, screen time, PA level/frequency, and intake of fruits and vegetables from baseline assessments. The information was designed to raise awareness and encourage parents to support their daughters' healthy eating and PA. 
Table 1

Intervention activities, behavior change strategies, and target constructs of "Healthy Habits, Healthy Girls".

\begin{tabular}{|c|c|c|c|c|}
\hline Activities & Intensity & Description (material) & Behavior change strategy (products) & Target construct (results) \\
\hline $\begin{array}{l}\text { Enhanced PE } \\
\text { classes }\end{array}$ & $40 \times 45$ minutes & $\begin{array}{l}\text { PE classes were delivered by PE teachers } \\
\text { for } 6 \text { months. The classes included a range } \\
\text { of lifetime and lifestyle PA organized into } \\
5 \text { week units. Activities included warm-up/ } \\
\text { stretching, jogging, dance, skipping rope, } \\
\text { and resistance training }\end{array}$ & $\begin{array}{l}\text { Efficient development of specific goals; } \\
\text { Information on consequences of health } \\
\text { behaviors; Efficient intention formation; } \\
\text { Have instructions on the health } \\
\text { behaviors; Overcoming barriers; General } \\
\text { motivation; Progressive tasks }\end{array}$ & $\begin{array}{l}\text { Self-efficacy; Social support; } \\
\text { Intentions; Outcome } \\
\text { expectations }\end{array}$ \\
\hline $\begin{array}{l}\text { PA during } \\
\text { recess }\end{array}$ & $14 \times 15$ minutes & $\begin{array}{l}\text { Participants invited other students to } \\
\text { engage in PA sessions during recess. } \\
\text { Participants directed the sessions with } \\
\text { lifetime PA learned during PE classes, } \\
\text { under the PE teacher's supervision }\end{array}$ & $\begin{array}{c}\text { Friends role modeling or demonstration } \\
\text { of behaviors; Progressive tasks; Efficient } \\
\text { identification as a role model }\end{array}$ & $\begin{array}{c}\text { Peer support; Self-efficacy; } \\
\text { Outcome expectations and } \\
\text { expectancies }\end{array}$ \\
\hline $\begin{array}{l}\text { Weekly } \\
\text { nutritional } \\
\text { and PA key } \\
\text { messages }\end{array}$ & $10 \times 20$ minutes & $\begin{array}{l}\text { Participants received nutritional and PA } \\
\text { messages for } 10 \text { weeks, delivered by } \\
\text { trained research assistants during recess } \\
\text { for } 15-20 \text { minutes. The messages were } \\
\text { delivered once a week and the topics } \\
\text { followed the agenda of the nutrition and } \\
\text { PA handbooks, i.e., once every other week } \\
\text { on nutrition and PA }\end{array}$ & $\begin{array}{l}\text { Information on nutrition and PA } \\
\text { behaviors; Progressive tasks; } \\
\text { General motivation; Friends role } \\
\text { modeling/friends change; Adequate } \\
\text { self-monitoring of the behaviors; } \\
\text { Overcoming barriers }\end{array}$ & $\begin{array}{l}\text { Self-efficacy; Social support; } \\
\text { Behavioral strategies; } \\
\text { Home environment; } \\
\text { Outcome expectations and } \\
\text { expectancies }\end{array}$ \\
\hline $\begin{array}{l}\text { Nutrition and } \\
\text { PA handbook }\end{array}$ & 10 weeks & $\begin{array}{l}\text { The girls received the } 10 \text { key nutritional } \\
\text { and PA messages through a handbook. } \\
\text { The handbook has information, home } \\
\text { challenges, and family activities planned to } \\
\text { promote nutrition and PA for participants } \\
\text { and their families }\end{array}$ & $\begin{array}{l}\text { Information on nutrition and PA } \\
\text { behaviors; Adequate self-monitoring of } \\
\text { the behaviors; Family support/change }\end{array}$ & $\begin{array}{c}\text { Self-efficacy; Social } \\
\text { support; Intentions; } \\
\text { Behavioral strategies; } \\
\text { Outcome expectations and } \\
\text { expectancies }\end{array}$ \\
\hline $\begin{array}{l}\text { Interactive } \\
\text { seminars }\end{array}$ & $3 \times 60$ minutes & $\begin{array}{l}\text { Girls attended on three interactive } \\
\text { workshops delivered by two dietitians, } \\
\text { which reinforced the } 10 \text { nutrition and PA } \\
\text { keys messages. The seminars reinforced } \\
\text { the nutrition and PA guidelines and } \\
\text { behavioral strategies to support students } \\
\text { PA sessions during recess and at home }\end{array}$ & $\begin{array}{l}\text { Information on nutrition and PA } \\
\text { behaviors; Adequate self-monitoring of } \\
\text { behaviors; Social support/social change; } \\
\text { Overcoming barriers }\end{array}$ & $\begin{array}{l}\text { Self-efficacy; Behavioral } \\
\text { strategies; Social support; } \\
\text { Home environment; } \\
\text { Intentions; Outcome } \\
\text { expectations and } \\
\text { expectancies }\end{array}$ \\
\hline $\begin{array}{l}\text { Nutrition } \\
\text { workshops }\end{array}$ & $3 \times 90$ minutes & $\begin{array}{l}\text { Girls participated in three workshops } \\
\text { delivered by two dietitians that provided } \\
\text { dietary information and focused } \\
\text { preparation of healthy and inexpensive } \\
\text { meals. Activities were planned to develop } \\
\text { lifetime nutrition skills that help maintain } \\
\text { healthy nutrition and included: energy } \\
\text { balance and kilocalories concept, food } \\
\text { label information, recipe changes and } \\
\text { preparations, the "diet" and "light" } \\
\text { concepts, adequate food portion size, } \\
\text { food pyramid, and smart food choices }\end{array}$ & $\begin{array}{l}\text { Food and nutrition information; Role } \\
\text { modeling or demonstrate on behaviors; } \\
\text { Progressive tasks }\end{array}$ & $\begin{array}{l}\text { Self-efficacy; Intentions; } \\
\text { Home environment; } \\
\text { Outcome expectations and } \\
\text { expectancies }\end{array}$ \\
\hline
\end{tabular}

(continues) 
Table 1 (continued)

\begin{tabular}{|c|c|c|c|c|}
\hline Activities & Intensity & Description (material) & Behavior change strategy (products) & Target construct (results) \\
\hline $\begin{array}{l}\text { Parents' } \\
\text { newsletter }\end{array}$ & $\begin{array}{l}\text { 2nd and } 3 \text { rd } \\
\text { school terms } \\
\text { (4 total) }\end{array}$ & $\begin{array}{l}\text { Parents/caregivers received newsletters } \\
\text { describing the study, their daughters' } \\
\text { baseline health behaviors and nutritional } \\
\text { status, and encouragement to support } \\
\text { their children's healthy nutrition and PA } \\
\text { behaviors at home }\end{array}$ & $\begin{array}{l}\text { Feedback on the girls' performance; } \\
\text { Family support on healthy behaviors; } \\
\text { General motivation; Having information } \\
\text { on nutrition and PA behaviors }\end{array}$ & $\begin{array}{l}\text { Self-efficacy; Social support; } \\
\text { Home environment; } \\
\text { Outcome expectations and } \\
\text { expectancies }\end{array}$ \\
\hline Text messages & $\begin{array}{l}\text { 2nd and 3rd } \\
\text { terms twice/ } \\
\text { week }\end{array}$ & $\begin{array}{l}\text { Twice weekly the girls received text } \\
\text { messages encouraging healthy eating, } \\
\text { more PA, and less time in sedentary } \\
\text { activities. In each intervention school, a } \\
\text { text message group was created for more } \\
\text { interaction between participants and } \\
\text { the moderator. Girls without cell phones } \\
\text { received these messages via e-mail }\end{array}$ & $\begin{array}{c}\text { Plan social support/social change; } \\
\text { General motivation; Information on } \\
\text { nutrition and PA behaviors; Overcoming } \\
\text { barriers }\end{array}$ & $\begin{array}{l}\text { Social support; Outcome } \\
\text { expectations and } \\
\text { expectancies; Self-efficacy }\end{array}$ \\
\hline $\begin{array}{l}\text { Dietary/ PA } \\
\text { diaries }\end{array}$ & 3rd term & $\begin{array}{c}\text { Girls were encouraged to use dietary and } \\
\text { PA diaries to encourage goal-setting and } \\
\text { self-monitoring behaviors }\end{array}$ & $\begin{array}{l}\text { Efficient self-monitoring; Efficient specific } \\
\text { goal-setting }\end{array}$ & $\begin{array}{l}\text { Self-efficacy; Outcome } \\
\text { expectations and } \\
\text { expectancies; Behavioral } \\
\text { strategies }\end{array}$ \\
\hline
\end{tabular}

PA: physical activity; PE: physical education.

Table 2

"Healthy Habits, Healthy Girls" nutrition and physical activity messages.

\begin{tabular}{lc}
\hline Week & Message \\
\hline 1 & Eat fruit and vegetables every day \\
2 & Do physical exercise, respect your limits \\
3 & Eat a healthy breakfast every day \\
4 & Do physical exercise with family and friends \\
5 & Control the size of meal portions and sit while eating \\
6 & Reduce your chair time during recess, after school, and weekends \\
8 & Eat less "junk food" and munch less \\
9 & Identify your excuses for not doing physical exercise \\
10 & Drink water and replace sodas and artificial juices with water, homemade natural fruit juices, \\
& and coconut water \\
\hline
\end{tabular}

\section{- Text messages}

Text messages were sent to students twice a week (terms $2 / 3$ and school holidays) to encourage them to be physically active and eat healthy. The text messages did not require a response from the students and were both motivational and informational. Messages were sent at appropriate times for specific topics. For example, messages to encourage healthy snacks during the FIFA World Cup games were sent one hour before the opening whistle.
To facilitate implementation of the "Healthy Habits, Healthy Girls" program, cooperating teachers were invited to attend a two-day workshop at the university. The workshop was designed to help teachers deliver the intervention components, with findings from the baseline assessments reported back to teachers. All the intervention schools received foods for the nutrition workshops and recipe cards. For the PE classes, some activities did not require equipment and were adapted to use body movements only. For music, some students and teachers 
brought their favorite songs from home, making the activity more enjoyable.

To prevent compensatory rivalry and resentful demoralization, the control school received a condensed version of the 12-month follow-up assessments. The condensed version of the program includes professional learning workshops and intervention materials.

\section{Outcomes}

A protocol manual with specific instructions for conducting all assessments was used by RA during baseline data collection and will be used during follow-up assessments to ensure consistency. Physical assessments were conducted with a sensitive approach (i.e., weight measured out of the view of other students) and questionnaires were completed after the physical assessments under exam-like conditions. Socio-demographic information, primary and secondary outcomes, and hypothesized mediators of behavior change were measured.

\section{- Primary outcomes}

\section{a) Height and weight}

Weight was measured to the nearest $0.1 \mathrm{~kg}$ barefoot, in light clothing using a portable digital scale (Plenna, Brazil), and height was recorded to the nearest $0.1 \mathrm{~cm}$ using a portable stadiometer (Alturaexata, Brazil). BMI followed the standard equation (weight $[\mathrm{kg}] /$ height $\left[\mathrm{m}^{2}\right]$ ), and BMI zscore was calculated by least mean squares (LMS) 15, a method used to build distribution curves of anthropometric outcomes like weight and height. The core assumption of this method is that independent data with positive values in each age can be used to normalize the data presented in asymmetric distributions 16 .

\section{b) Waist circumference}

Waist circumference was measured to the nearest $0.1 \mathrm{~cm}$ using a non-extensible steel tape measure (TBW, Brazil) aligned on the skin with the umbilicus.

\section{- Secondary outcomes}

\section{a) Physical activity}

PA was assessed using an adapted and validated questionnaire for Brazilian adolescents 17 on the frequency and intensity of PA in one week. Subjects reported the number of times of light-tovigorous PA for at least 30 minutes in a seven- day period (weekdays plus weekends). The girls were classified in three categories according to the Global Recommendations on Physical Activity and Health 18 for adolescents. The categories were inactive ( $<30$ minutes per week), insufficiently active $(<300$ minutes per week), and active (>300 minutes per week).

\section{b) Dietary behavior}

Dietary behavior was assessed with the Brazilian Food Frequency Questionnaire based on the Food Pyramid (BFFQ-FP), a 49-item semi-quantitative food-frequency questionnaire (FFQ) previously tested for reliability and relative validity 19. Food items were organized in the pyramid's food groups. A list of the most common foods/beverages consumed by the adolescents was at the back of the questionnaire. Subjects were asked about their consumption in the previous 12 months. Options ranged from "never" to "at least twice a day" for all items.

\section{c) Sedentary behaviors}

Subjects reported the time spent during the weekdays and weekends in the following activities: watching TV/video/DVD and computer use for leisure activities and reading/homework.

\section{d) PA and social-cognitive dietary mediators (Table 3)}

The study used social cognitive scales for dietary and PA behaviors based on constructs from SCT 13, adapted from an Australian version 20 and validated for Brazilian adolescents 21,22. Participants completed separate nutritional and PA scales for self-efficacy, intentions, support from family and friends, environment perceptions, behavioral strategies, and outcome expectations and expectancies. Selected subscales (body satisfaction, weight control behaviors, binge eating, and teasing about weight by family and peers) from the New Moves study questionnaire 23 were included as potential outcomes and mediators of diet and PA behaviors.

\section{e) Process evaluation}

A detailed process evaluation will be done at the end of the "Healthy Habits, Healthy Girls" trial, including achievement of target sample size, retention rates at 7 - and 12-month follow-ups, attendance in activities, intervention fidelity, acceptability, and program satisfaction. 
Table 3

Scales of dietary and physical activity mediators.

\begin{tabular}{|c|c|c|c|}
\hline Variables & Descriptions and example items & Range (items) & ICC $(95 \% \mathrm{Cl})$ \\
\hline Self-efficacy & $\begin{array}{l}\text { Confidence in the ability to overcome barriers to adopt and } \\
\text { maintain healthy behaviors }\end{array}$ & & \\
\hline Dietary example & "I find it easy to consume five portions of fruits every day" & 5 & $0.77(0.51-0.91)$ \\
\hline Example of PA & $\begin{array}{l}\text { "It's very hard for me to practice PA when it's very hot, very } \\
\text { cold, or raining" }\end{array}$ & 5 & $0.62(0.24-0.84)$ \\
\hline Intention & Intentions to adopt healthy behaviors & & \\
\hline Dietary example & $\begin{array}{l}\text { "Do you plan to choose low-fat foods and/or preparations } \\
\text { whenever you have a chance?" }\end{array}$ & 5 & $0.93(0.87-0.97)$ \\
\hline Example of PA & $\begin{array}{l}\text { "Do you plan to practice PA everyday or most days of the } \\
\text { week?" }\end{array}$ & 1 & - \\
\hline Social support (friends/family) & $\begin{array}{l}\text { Parents' and friends' influence, reinforcing healthy behaviors } \\
\text { through encouragement and role modeling }\end{array}$ & & \\
\hline Dietary example & $\begin{array}{l}\text { "Do your friends support you in choosing healthy foods when } \\
\text { you eat meals together?" and "Do your parents sometimes } \\
\text { prepare healthy homemade meals dishes?" }\end{array}$ & 5 & $0.80(0.61-0.92)$ \\
\hline Example of friends' support for PA & $\begin{array}{l}\text { "Do you practice PA with your friends during recess, after } \\
\text { school, or on weekends?" }\end{array}$ & 3 & $0.82(0.60-0.93)$ \\
\hline Example of parents' support for PA & Do your parents buy things to support your PA?" & 4 & $0.84(0.67-0.93)$ \\
\hline Behavioral strategies & $\begin{array}{l}\text { Self-reinforcement of healthy behaviors by setting goals, } \\
\text { monitoring behavior, and self-reward }\end{array}$ & & \\
\hline Dietary example & $\begin{array}{l}\text { "Do you find ways to make fruits and vegetables more } \\
\text { enjoyable?" }\end{array}$ & 6 & $0.73(0.49-0.89)$ \\
\hline Example of PA & "Do you find ways to make PA more enjoyable? & 5 & $0.92(0.85-0.97)$ \\
\hline Situation & Individual's perception of their environment & & \\
\hline Dietary example & "There are often fruits and vegetables at home" & 6 & $0.91(0.83-0.96)$ \\
\hline Example of PA & $\begin{array}{l}\text { "It's difficult for me to practice PA in my neighborhood due } \\
\text { to violence and crime" }\end{array}$ & 6 & $0.70(0.42-0.87)$ \\
\hline Outcome expectations & $\begin{array}{l}\text { Anticipated benefits of healthy behaviors, e.g.: "Healthy eating } \\
\text { can reduce my risk for some conditions and diseases" }\end{array}$ & & \\
\hline Dietary example & $\begin{array}{l}\text { "Healthy eating can reduce my risk for some conditions and } \\
\text { diseases" }\end{array}$ & 5 & $0.85(0.72-0.94)$ \\
\hline Example of PA & "Regular physical activity helps me manage stress" & 5 & $0.91(082-0.96)$ \\
\hline Outcome expectancies & Value placed on anticipated benefits of healthy behaviors & & \\
\hline Dietary example & $\begin{array}{l}\text { "How important is it for you to reduce the risk of these } \\
\text { conditions and diseases?" }\end{array}$ & 5 & $0.65(0.32-0.85)$ \\
\hline Example of PA & "How important is it for you to manage stress?" & 5 & $0.69(0.40-0.87)$ \\
\hline
\end{tabular}

95\%Cl: 95\% confidence interval; ICC: intraclass correlation coefficient; PA: physical activity.

\section{Statistical methods}

Statistical analysis of the primary and secondary outcomes will be conducted with linear mixed models using IBM SPSS Statistics for Apple Macintosh, version 21.0 (IBM Co., Armonk, USA), with alpha levels set at $\mathrm{p} \leq 0.05$. The models will be used to assess the impact of treatment (intervention vs. control), time (treated as categorical with levels at baseline and 7 months) and the group-time interaction, these three terms forming the base model. The models will be specified to adjust for the data's clustered nature and will include all participants randomized in the analysis. Differences between those who complete the study and dropout will be examined using chi-square and independent sample t-tests. Additional moderators of intervention effects (e.g., ethnicity and socioeconomic status) will be explored using linear mixed models with interac- 
tion terms. Hypothesized mediators of PA and sedentary behavior change will be analyzed with multilevel linear analysis and a product-of-coefficients test, appropriate for cluster randomized controlled trials 7,8 .

\section{Results}

Ten schools were recruited and 253 participants were assessed at baseline, representing $95.1 \%$ of the target sample size. Results of most outcomes are presented as means \pm standard deviations, exception for categorical outcomes (i.e., nutritional status and ethnicity) (Table 4). There were no statistically significant differences between the control and intervention groups for most demographic or outcome variables, except for age $(\mathrm{p}=0.000)$ and waist circumference $(\mathrm{p}=0.014)$. Most adolescent girls in the "Healthy Habits, Healthy Girls" group were born in the city of São Paulo (88\%) and reported their race/skin color as white (55.6\%), followed by brown (26.4\%). A high percentage of the girls were overweight and/or obese (32.4\% intervention group vs. $23.4 \%$ control group). High proportions of the girls from both groups failed to meet current recommendations for moderate PA (43.2\% intervention vs. $54.2 \%$ control groups), vigorous PA (73.2\% vs. $79.3 \%$ ), or screen time (75.4\% vs. $79.3 \%$ ). The girls reported mean intake of 2,223.36 \pm 794.48 kilocalories/day (intervention group) and 2,300.09 \pm 1,012.35 kilocalories/day (control group).

\section{Discussion}

The "Healthy Habits, Healthy Girls" study is a randomized controlled trial testing a novel cognitive behavioral skills model aimed to promote healthy eating, PA, mental health, and social skills and reduce sedentary behaviors and prevent unhealthy weight in a sample of Brazilian adolescent girls from disadvantaged backgrounds. Overweight rates were higher in adolescents from disadvantaged backgrounds than those from non-disadvantaged communities.

Most published school-based obesity intervention programs have been conducted in Australia 7,8 and the United States 24,25.

Preventing unhealthy weight gain in adolescents is difficult 7 , and many school-based intervention programs in Brazil have failed to achieve significant changes in health behaviors or the prevention of weight gain $26,27,28$. The ineffectiveness of numerous interventions to reduce obesity challenges the wisdom of allocating scarce resources to school-based interventions 29 .
Several reasons for the lack of success of the Brazilian intervention programs should be analyzed. First, there is a scarcity of rigorous theorybased methodologies to support intervention strategies for teenagers 28,29 . Such theories are important for guiding interventions to foster positive behavior change. Evidence suggests that theory-based interventions are more effective than non-theoretical approaches 30 . For example, social cognitive theories are useful for explaining eating and PA behaviors, by showing that behaviors are influenced by social and psychological determinants 31 .

Self-efficacy is the key determinant of health behavior in SCT, referring to the individual's ability to make healthy choices 32 . Both crosssectional and longitudinal studies have demonstrated the importance of self-efficacy in explaining adolescents' dietary and PA behaviors $33,34,35,36$. For example, higher dietary self-efficacy can correlate with higher intake of core foods and lower intake of non-core foods. Higher PA self-efficacy can correlate with increased light or moderate-to-vigorous PA and/or reduced sedentary activities.

Intentions and goals are also considered direct antecedents of a specific behavior. A review concluded that dietary intentions were one of the strongest psychosocial correlates of behavior in adolescents 37 . Similar RCTs have shown that intentions were inversely associated with energy from non-core foods, percentage of energy intake from saturated fats, and screen time and positively associated with percentage intake from core foods and moderate and vigorous PA 35,36. Good intentions for healthy eating and PA can be translated into behavior.

Other levels of influence are family and friends and the home environment, considered potential barriers/facilitators for healthy eating ${ }^{36}, \mathrm{PA}$, and sedentary behaviors 35 . Finally, the NEAT Girls study 36 demonstrated the importance of outcome expectations and expectancies. Studies rarely assess the difference between outcome expectations and expectancies. Analyzing these constructs is important because individuals, especially adolescents, may recognize the benefits of healthy eating/ PA (i.e., outcome expectations), but unless they consider such benefits valuable (outcome expectancies), they are unlikely to be motivated to adopt healthy behaviors.

Social ecological models of health behavior provide frameworks for intervention strategies by addressing different individual and environmental levels of influence. Clearly, continued efforts are needed for theoretically guided interventions to help develop a stronger evidence 
Table 4

Baseline characteristics of the study sample. São Paulo, Brazil, 2014.

\begin{tabular}{|c|c|c|c|c|c|}
\hline & \multicolumn{2}{|c|}{ "Healthy Habits, Healthy Girls" ( $n=135)$} & \multicolumn{2}{|c|}{ Control group $(n=111)$} & \multirow[t]{2}{*}{ p-value } \\
\hline & Mean (SD) & ICC $(95 \% \mathrm{Cl})$ & Mean (SD) & ICC $(95 \% \mathrm{Cl})$ & \\
\hline Age (years) & $16.32(0.78)$ & $16.19-16.45$ & $15.70(0.82)$ & $15.55-15.86$ & 0.000 \\
\hline \multicolumn{6}{|l|}{ Anthropometric measurements } \\
\hline Weight (kg) & $59.64(12.15)$ & $57.63-61.66$ & $55.19(11.69)$ & $52.99-57.39$ & 0.401 \\
\hline Height (m) & $1.62(0.06)$ & $1.60-1.63$ & $1.60(0.06)$ & $1.56-1.61$ & 0.486 \\
\hline Waist circumference $(\mathrm{cm})$ & $76.41(10.84)$ & $74.61-78.21$ & $71.46(10.67)$ & $69.45-73.46$ & 0.014 \\
\hline BMI $\left(\mathrm{kg} / \mathrm{m}^{2}\right)$ & 21.81 (4.09) & 22.13-23.49 & $21.44(3.82)$ & $20.73-22.16$ & 0.247 \\
\hline \multirow[t]{2}{*}{ Total dietary intake (kcal) } & $2,224.36(794.48)$ & $2,092.55-2,356.16$ & $2,300.09(1,012.35)$ & $2,109.66-2,490.51$ & 0.506 \\
\hline & n & $\%$ & $n$ & $\%$ & $p$-value \\
\hline \multicolumn{6}{|l|}{ PA classification * } \\
\hline Moderate PA & & & & & 0.087 \\
\hline Inactive & 60 & 43.2 & 60 & 54.1 & \\
\hline Insufficiently active & 76 & 53.5 & 44 & 39.6 & \\
\hline Active & 6 & 4.2 & 7 & 6.3 & \\
\hline Vigorous PA & & & & & 0.084 \\
\hline Inactive & 104 & 73.2 & 94 & 84.7 & \\
\hline Insufficiently active & 33 & 23.2 & 14 & 12.6 & \\
\hline \multirow[t]{2}{*}{ Active } & 5 & 3.5 & 3 & 2.7 & \\
\hline & $\mathbf{n}$ & $\%$ & $\mathbf{n}$ & $\%$ & p-value \\
\hline \multicolumn{6}{|l|}{ Sedentary activities ** } \\
\hline Sedentary activities (hours/day) & & & & & 0.461 \\
\hline$<2$ & 35 & 24.6 & 23 & 20.7 & \\
\hline \multirow[t]{2}{*}{$>2$} & 107 & 75.4 & 88 & 79.3 & \\
\hline & n & $\%$ & n & $\%$ & $p$-value \\
\hline \multicolumn{6}{|l|}{ BMI classification } \\
\hline Nutritional status & & & & & 0.102 \\
\hline Underweight & 5 & 3.5 & 1 & 0.9 & \\
\hline Normal weight & 91 & 64.1 & 84 & 75.7 & \\
\hline Overweight & 33 & 23.2 & 22 & 19.8 & \\
\hline Obese & 13 & 9.2 & 4 & 3.6 & \\
\hline
\end{tabular}

95\% Cl: 95\% confidence interval; BMI: body mass index; ICC: intraclass correlation ocefficient; PA: physical activity; SD: standard deviation.

* Classification of physical activity in three levels according World Health Organization (WHO) guidelines: inactive, insufficiently active, and active.

Active defined as $\geq 300$ hours/week;

** Sedentary activities = Screen time: TV, DVDs, and computer or other electronic devices (e.g., tablets and smartphones).

base for mediators of behavior change among youth 36 .

An intervention program should be differentiated according to the target group in order to be as effective as possible in the prevention of unhealthy weight gain in children and adolescents. Such programs should include combined dietary and PA interventions, family involvement, and long-term interventions (at least 6 months), as opposed to short-term interventions (a few weeks or months) 8,38 .

Evidence suggests that youth interventions should be differentiated by gender, age, and socioeconomic status 7,8. For example, decline in PA and unhealthy eating behaviors can become more evident during adolescence, especially 
among girls from disadvantaged backgrounds, placing this group at even greater risk of unhealthy weight 39 . Although some studies in Brazil have targeted both female and male adolescents enrolled in public schools located in low-income communities 27,28 , to our knowledge this is the first Brazilian theory-based multi-component intervention to specifically target adolescent girls. Previous school-based interventions in Brazil have shown some promise, but the results have been inconsistent 3,27 .

Therefore, an advantage of theory-based targeted interventions is that they can be tailored to the characteristics of certain groups. The NEAT Girl studies have targeted inactive adolescent girls from low-income backgrounds ("at risk" for obesity). Although NEAT Girls did not alter the primary outcome (BMI), it presented small changes in other health behaviors such as PA, screen time, and dietary intake 11,40. Likewise, the New Moves intervention program targeted adolescent girls who were overweight or "at risk" for obesity 23 . Both interventions were intensive. Unlike NEAT Girls 11 , New Moves 23 did not include a parental component. Parents play an important role in shaping their children's eating and PA behaviors and should be included in multilevel approaches to obesity prevention in youth ${ }^{8}$.

More than twenty percent of the girls were overweight (23.2\% intervention vs. $19.8 \%$ control) or obese $(9.2 \%$ vs. $3.6 \%)$. This pattern is consistent with a secular trend using data from 2008-2009 in the Brazilian National Household Budget Survey, in which the relationship between socioeconomic status and overweight was slightly more marked in adolescent girls 41 . The recruitment strategy of "Healthy Habits, Healthy Girls" involved girls in the target school-based program without stigmatizing them, since the initial measures were taken very privately and discreetly, a process that will continue throughout the study 7 .

"Healthy Habits, Healthy Girls" did not show significant baseline differences between the intervention and control groups for most demographic or outcome variables. Similar results were found in the Australian NEAT Girls randomized controlled trial 8 . Randomization prevents differences between the groups at the beginning of the study, generating groups that are roughly comparable in terms of known and unknown prognostic variables 42 .

Although age $(p=0.000)$ and waist circumference $(p=0.014)$ differed significantly between the groups, this may not affect post-intervention and follow-up measurements. Adolescence ranges from 10 to 19 years of age. During early adolescence (10 to 14 years) or puberty, a rapid growth spurt occurs, secretion of several hormones in- creases, and secondary sexual characters appear (sexual maturation). This process slows down in late adolescence (15 to 19 years) 43 . The study sample's mean age (16.32 in the intervention group and 15.70 in the control group) thus places the girls in late adolescence.

As for the difference in waist circumference, this measurement is considered a complementary outcome together with BMI, which did not show a significant difference. Many RCTs use BMI as the primary outcome. However, postintervention and follow-up measurements did not show significant differences 11,23 . Nevertheless, the ATLAS Boys study 8 used both BMI and waist circumference as primary outcomes. Waist circumference is more sensitive than BMI for detecting changes in body fat composition. Special attention should be given to evaluation of this outcome for future measurements, along with other body composition outcomes.

Most nutritional and/or PA intervention programs in Brazil focus mainly on spreading information on the benefits of certain foods, nutrients, and PA against the harmful effects of other behaviors. New information on nutrition and/ or PA should enhance individual knowledge, resulting in better health behaviors 27,28 . However, the literature shows the weakness of evidence concerning this type of strategy ${ }^{3}$. A qualitative study 44 with adolescents in low-income areas in São Paulo showed that adequate knowledge on healthy eating failed to translate into adequate health behaviors. More than $50 \%$ of adolescents reported an adequate understanding of healthy eating according to principles of the Brazilian food guide pyramid and smart food choices 9 . However, the same teenagers reported not adhering to healthy eating behaviors for several reasons, including food preferences, peer influence, food prices, and easy access to unhealthy foods (e.g., at candy stores) 45 . The authors concluded that the focus of traditional interventions related to basic information on dissemination of health knowledge requires urgent modification. Intervention strategies focusing on behavior changes and with methodologically rigorous trials should be used due to difficulties in achieving healthy habits; healthy habits that are incorporated early are more like to be consolidated in later life (adulthood and old age) 44 .

The "Healthy Habits, Healthy Girls" program emphasized the need for multilevel interventions, including a number of components designed to support dietary and PA behavior change, including text messages, nutritional workshops, and strategies to engage parents to support their children's PA and dietary behaviors. Such methods should help increase motivation and reduce the 
decline in PA and enhance healthy eating by adolescent girls. To our knowledge, "Healthy Habits, Healthy Girls" is the first school-based nutritional and PA program for low-income Brazilian adolescent girls enrolled in public high schools.

The study's strengths include discussions with the NEAT Girls team to deliver the intervention in Brazil and the collection of rigorous, highly reliable dietary, PA, and anthropometric data. However, some limitations need to be addressed. The lack of an economic evaluation prevents determination of the intervention's cost-effectiveness. Since the intervention was targeted, the findings may not be generalizable to other groups (e.g., males and teens from other socioeconomic strata) or to the general population. Despite the limitations, the study can serve as a framework for further research in Brazil or elsewhere in the world, particularly in other developing countries.

\section{Resumen}

El propósito de este trabajo es describir el diseño del estudio, protocolo y resultados iniciales del programa "Hábitos Saludables, Niñas Saludables". La intervención se evaluó a través de un ensayo controlado aleatorio en 10 escuelas de São Paulo, Brasil. Las variables se recogieron y evaluaron al inicio del estudio y serán evaluadas tras 7 y 12 meses en base a: índice de masa corporal; circunferencia de cintura; dieta; factores mediadores cognitivos-sociales de nutrición y actividad física; actividad física; sedentarismo; auto-percepción y autoestima. Los resultados iniciales demostraron que el $32,4 \%$ y el 23,4\% del grupo intervención y control tenían sobrepeso, y para ambos grupos un mayor porcentaje no cumplían con las recomendaciones diarias de actividad física y tiempo dedicado a actividades de ocio. La mayoría de las variables, con excepción edad $(p=0,000)$ $y$ circunferencia de cintura $(p=0,014)$, no presentaron diferencias entre grupos. Existe un cierto vacío en la literatura brasileña sobre protocolos de ensayos controlados aleatorios para prevenir la obesidad en jóvenes. Este tipo de trabajos podrían ser una contribución para este campo.

Adolescente; Conducta Alimentaria; Actividad Motora; Obesidad

\section{Conclusion}

The article outlined the rationale, study protocol, and baseline results of the "Healthy Habits, Healthy Girls" intervention for adolescent girls in low-income communities. "Healthy Habits, Healthy Girls" is an innovative, school-based obesity prevention intervention focusing on healthy eating and PA in adolescent girls. The intervention has a strong theoretical basis and incorporates lifestyle and lifetime activities through 10 key health messages. The findings and experience gained in this study should help guide future school-based adolescent obesity-prevention programs in Brazil and provide insight for other developing countries.

\section{Contributors}

A. C. B. Leme collaborated in defining the research question, designing the study, and obtaining ethical approval, developed the intervention materials, recruited the participants, and collaborated in implementing the study, drafting the manuscript, and approving the final version. S. T. Philippi collaborated in defining the research question, designing the study, and obtaining ethical approval, supervised the study's implementation, and collaborated in drafting the manuscript and approving the final version.

\section{Acknowledgments}

The authors wish to thank Associate Professor David R. Lubans (University of Newcastle, Australia) and Deborah Dewar, $\mathrm{PhD}$, for the support and development of the Brazilian adaptation of the "Healthy Habits, Healthy Girls" NEAT Girls Program. 


\section{References}

1. Levy RB, Castro IRR, Cardoso LO, Tavares LO, Sardinha LMV, Gomes FS, et al. Consumo e comportamento alimentar entre adolescentes brasileiros: pesquisa nacional de saúde do escolar (PeNSE), 2009. Ciênc Saúde Coletiva 2010; 15 Suppl 2: 3085-97.

2. Hallal PC, Knuth AG, Cruz DKA, Mendes MI, Malta DC. Prática de atividade física em adolescentes brasileiros. Ciênc Saúde Coletiva 2010; 15 Suppl 2:3035-42

3. Friedrich RR, Schuch I, Wagner MB. Efeito de intervenções sobre o índice de massa corporal em escolares. Rev Saúde Pública 2012; 46:551-60.

4. Sacchetti R, Ceciliani A, Garulli A, Dallolio L, Beltrami P, Leoni E. Effects of a 2-year school-based intervention of enhanced physical education in the primary school. J Sch Health 2013; 83:639-46.

5. Brown T, Summerbell C. Systematic review of school-based interventions that focus on changing dietary intake and physical activity levels to prevent childhood obesity: an update to the obesity guidance produced by the National Institute for Health and Clinical Excellence. Obes Rev 2009; 10:110-41.

6. Campbell MK, Elbourne DR, Altman DG. CONSORT Statement: extension to cluster randomised trials. BMJ 2004; 328:702-8.

7. Lubans DR, Morgan PJ, Dewar D, Collins CE, Plotnikoff RC, Okely AD, et al. The Nutrition and Enjoyable Activity for Teen Girls (NEAT girls) randomized controlled trial for adolescent girls from disadvantaged secondary schools: rationale, study protocol, and baseline results. BMC Public Health 2010; 10:652.

8. Smith JJ, Morgan PJ, Plotnikoff RC, Dally KA, Salmon J, Okely AD, et al. Rationale and study protocol for the 'Active Teen Leaders Avoiding Screentime' (ATLAS) group randomized controlled trial: an obesity prevention intervention for adolescent boys from schools in low-income communities. Contemp Clin Trials 2014; 37:106-19.

9. Philippi ST. Pirâmide dos alimentos: fundamentos básicos da nutrição. Barueri: Manole; 2014.

10. Hallal PC, Andersen LB, Bull FC, Guthold R, Haskell W, Ekelund U. Global physical activity levels: surveillance progress, pitfalls, and prospects. Lancet 2012; 380:247-57.

11. Lubans DR, Morgan PJ, Okely AD, Dewar D, Collins CE, Batterham M, et al. Preventing obesity among adolescent girls: one-year outcomes of the Nutrition and Enjoyable Activity for Teen Girls (NEAT Girls) cluster randomized controlled trial. Arch Pediatr Adolesc Med 2012; 166:821-7.

12. Bandura A. Social cognitive theory: an agentic perspective. Annu Rev Psychol 2001; 52:1-26.

13. Bandura A. Health promotion by social cognitive means. Health Educ Behav 2004; 31:143-64.

14. Abraham C, Michie S. A taxonomy of behavior change techniques used in interventions. Health Psychol 2008; 27:379-87.

15. de Onis M. Development of a WHO growth reference for school-aged children and adolescents. Bull World Health Organ 2007; 85:660-7.
16. Cole TJ, Green PJ. Smoothing reference centile curves: the LMS method and penalized likelihood. Stat Med 1992; 11:1305-19.

17. Sao-Joao TM, Rodrigues RCM, Gallani MCBJ, Miura CTP, Domingues GBL, Godin G. Adaptação cultural da versão brasileira do Godin-Shephard Leisure-Time Physical Activity Questionnaire. Rev Saúde Pública 2013; 47:479-87.

18. World Health Organization. Global recommendations on physical activity for health. Geneva: World Health Organization; 2010.

19. Martinez MF, Philippi ST, Estima C, Leal G. Validity and reproducibility of a food frequency questionnaire to assess food group intake in adolescents. Cad Saúde Pública 2013; 29:1795-804.

20. Dewar DL, Lubans DR, Plotnikoff RC, Morgan PJ. Development and evaluation of social cognitive measures related to adolescent dietary behaviors. Int J Behav Nutr Phys Act 2012; 9:36.

21. Leme ACB, Philippi ST. Cultural adaptation and psychometric properties of social cognitive scales related to adolescent dietary behaviors. Cad Saúde Colet (Rio J) 2014; 22:252-9.

22. Leme AC, Philippi ST, Dewar D. Cultural adaptation and psychometric evaluation of modernized Australian social cognitive measures for physical activity: Brazilian version. Journal of Sport Science 2014; 3:134-43.

23. Neumark-Sztainer DR, Friend SE, Flattum CF, Hannan PJ, Story MT, Bauer KW, et al. New movespreventing weight-related problems in adolescent girls: a group-randomized study. Am J Prev Med 2010; 39:421-32.

24. Bogart LM, Cowgill BO, Elliott MN, Klein DJ, Hawes-Dawson J, Uyeda K, et al. A randomized controlled trial of students for nutrition and exercise: a community-based participatory research study. J Adolesc Health 2014; 55:415-22.

25. Myers EF, Gerstein DE, Foster J, Ross M, Brown K, Kennedy E, et al. Energy balance for kids with play: design and implementation of a multi-component school-based obesity prevention program. Child Obes 2014; 10:251-9.

26. Guerra PH, Nobre MR, da Silveira JA, Taddei JA. School-based physical activity and nutritional education interventions on body mass index: a metaanalysis of randomised community trials - project PANE. Prev Med 2014; 61:81-9.

27. Cunha DB, de Souza BS, Pereira RA, Sichieri R. Effectiveness of a randomized school-based intervention involving families and teachers to prevent excessive weight gain among adolescents in Brazil. PLoS One 2013; 8:e57498.

28. Toral N, Conti MA, Slater B. A alimentação saudável na ótica dos adolescentes: percepções e barreiras à sua implementação e características esperadas em materiais educativos. Cad Saúde Pública 2009; 25:2386-94.

29. Khambalia AZ, Dickinson S, Hardy LL, Gill T, Baur LA. A synthesis of existing systematic reviews and meta-analyses of school-based behavioural interventions for controlling and preventing obesity. Obes Rev 2012; 13:214-33. 
30. Anderson-Bill ES, Winett RA, Wojcik JR. Social cognitive determinants of nutrition and physical activity among web-health users enrolling in an online intervention: the influence of social support, self-efficacy, outcome expectations, and selfregulation. J Med Internet Res 2011; 13:e28.

31. Plotnikoff RC, Costigan SA, Karunamuni N, Lubans DR. Social cognitive theories used to explain physical activity behavior in adolescents: a systematic review and meta-analysis. Prev Med 2013; 56:245-53.

32. Cerin E, Barnett A, Baranowski T. Testing theories of dietary behavior change in youth using the mediating variable model with intervention programs. J Nutr Educ Behav 2009; 41:309-18.

33. Ball K, MacFarlane A, Crawford D, Savige G, Andrianopoulos N, Worsley A. Can social cognitive theory constructs explain socio-economic variations in adolescent eating behaviours? A mediation analysis. Health Educ Res 2009; 24:496-506.

34. Pearson N, Ball K, Crawford D. Predictors of changes in adolescents' consumption of fruits, vegetables and energy-dense snacks. Br J Nutr 2011; 105:795-803.

35. Dewar DL, Morgan PJ, Plotnikoff RC, Okely AD, Batterham M, Lubans DR. Exploring changes in physical activity, sedentary behaviors and hypothesized mediators in the NEAT girls group randomized controlled trial. J Sci Med Sport 2014; 17:39-46.

36. Lubans DR, Plotnikoff RC, Morgan PJ, Dewar D, Costigan S, Collins CE. Explaining dietary intake in adolescent girls from disadvantaged secondary schools. A test of Social Cognitive Theory. Appetite 2012; 58:517-24.

37. McClain AD, Chappuis C, Nguyen-Rodriguez ST, Yaroch AL, Spruijt-Metz D. Psychosocial correlates of eating behavior in children and adolescents: a review. Int J Behav Nutr Phys Act 2009; 6:54.
38. Melnyk BM, Kelly S, Jacobson D, Belyea M, Shaibi G, Small L, et al. The COPE healthy lifestyles TEEN randomized controlled trial with culturally diverse high school adolescents: baseline characteristics and methods. Contemp Clin Trials 2013; 36:41-53.

39. Neumark-Sztainer D, Wall M, Story M, Standish AR. Dieting and unhealthy weight control behaviors during adolescence: associations with 10-year changes in body mass index. J Adolesc Health 2012; 50:80-6.

40. Collins CE, Dewar DL, Schumacher TL, Finn T, Morgan PJ, Lubans DR. 12 month changes in dietary intake of adolescent girls attending schools in low-income communities following the NEAT Girls cluster randomized controlled trial. Appetite 2014; 73:147-55.

41. Instituto Brasileiro de Geografia e Estatística. Pesquisa de Orçamentos Familiares 2008-2009: antropometria e estado nutricional de crianças, adolescentes e adultos no Brasil. Rio de Janeiro: Instituto Brasileiro de Geografia e Estatística; 2010.

42. Moher D, Hopewell S, Schulz KF, Montori V, Gøtzsche PC, Devereaux PJ, et al. CONSORT 2010 explanation and elaboration: updated guidelines for reporting parallel group randomised trials. BMJ 2010; 340:c869.

43. Garcia GCB, Gambardella AMD, Frutuoso MFP. Estado nutricional e consumo alimentar de adolescentes de um centro de juventude da cidade de São Paulo. Rev Nutr 2003; 16:41-50.

44. Leme ACB, Philippi ST, Toassa EC. Association of Brazilian adolescents with healthy eating: knowledge, perceptions and food choices. Food Nutr Sci 2011; 2:1036-42.

45. Leme ACB, Philippi ST, Toassa EC. O que os adolescentes preferem: os alimentos da escola ou os alimentos competitivos? Saúde Soc 2013; 22:456-67.

Submitted on 15/Sep/2014

Final version resubmitted on 05/Mar/2015 Approved on 16/Mar/2015 